\title{
LA SUCESIÓN PROCESAL O CAMBIO DE PARTES EN EL PROCESO CIVIL*
}

Alejandro Romero Seguel ${ }^{* *}$

\section{EXPLICACIÓN GENERAL}

Por distintas razones puede ocurrir que, durante el desarrollo del proceso, el demandante o el demandado sea reemplazado por otro sujeto que pasa a ocupar su sitio en el litigio, al haberse producido un cambio en la titularidad de los derechos subjetivos que conforman el objeto del proceso. El fenómeno recién descrito se designa como sucesión procesal o cambio de partes ${ }^{1}$.

Dicho de otro modo, la figura que nos ocupa es una proyección en el proceso de la institución general de la sucesión. Como lo expone Elorriaga, "Suceder a una persona es ocupar su lugar y recoger los derechos y obligaciones que a cualquier título le pertenecían, es decir, se sucede siempre que subsistiendo una obligación o un derecho subjetivo, cambia el sujeto, sea el titular o el obligado" ${ }^{\prime 2}$.

La sucesión procesal existe para responder a ciertas eventualidades que pueden surgir en la tramitación de un proceso, por el hecho de haberse producido una transferencia o una transmisión de la cosa litigiosa. No resulta razonable que, por la producción de alguno de esos eventos lo obrado devenga en ineficaz.

Atendiendo a la causa que la origina, se debe distinguir entre sucesión procesal por muerte de una de las partes y la sucesión procesal surgida por transferencia de la cosa litigiosa por acto entre vivos.

\footnotetext{
* Colaboración recibida el 17 de enero y aprobada el 2 de marzo de 2011.

${ }^{* *}$ Doctor en Derecho; Profesor de Derecho Procesal de la Universidad de los Andes. Correo electrónico: aromero@uandes.cl.

1 Sobre esta institución, entre otros, Ortells Ramos, Manuel, Derecho Procesal Civil, $10^{a}$ Edición, Thomson Reuters, Pamplona, 2010, pp. 165-170; Ramos Méndez, Francisco, La Sucesión Procesal, Hispano Europea, Barcelona 1974, pp. 2 y 4; MANDRIOLI, Crisanto, Corso de diritto processuale civile I, $8^{\text {a }}$ Edición, Giappichelli, Torino, 1991, pp. 49-56; MICHELI, Gian Antonio, Curso de Derecho Procesal Civil, Tomo I, Traducción de Sentís Melendo, Santiago, E.J.E.A., Buenos Aires, 1970, p. 212; PICArDI, Nicola, Manuale del Processo Civile, Giuffré Editore, Milán, 2006, pp. 187-205; FazzAları, Elio, Istituzioni di Diritto Processuale, $8^{a}$ Edición, Cedam, Milán, 1996, pp. 330-339; Proto PISANI, Andrea, Lezioni di Diritto Processuale Civile, Jovene, Napolés, 2006, pp. 388-402.
}

${ }^{2}$ Elorriaga de Bonis, Fabián, Derecho Sucesorio, LexisNexis, Santiago 2005, pp. 4-5. 


\section{Requisitos De La Sucesión Procesal}

Para que se produzca la sucesión procesal se deben cumplir los siguientes requisitos:

$\left.1^{\circ}\right)$ Que, después de producida la litispendencia, se provoque la transmisión o una transferencia del derecho litigioso que es objeto del proceso;

$2^{\circ}$ ) Que dicha transferencia o transmisión pueda generar, efectivamente, un cambio de partes ${ }^{3}, y$

$3^{\circ}$ ) Que, en la relación procesal pendiente se solicite y decrete el cambio de partes, antes que se dicte una sentencia que alcance el efecto de cosa juzgada. Esta exigencia se explica porque el cambio de la titularidad en los derechos subjetivos no se proyecta automáticamente al proceso pendiente, tal como se pasa explicar.

\section{LA SUCESIÓN PROCESAL POR MUERTE DE UNA DE LAS PARTES}

\section{Régimen general}

La muerte constituye un acontecimiento imprevisible e inevitable, que puede alcanzar a una persona que tenga la calidad de parte en la relación procesal.

En principio, los herederos del causante tienen una vocación a la continuación del proceso donde su causahabiente era parte (art. 951 y 1097 CC). Sin embargo, la continuación del juicio por los herederos dependerá de la actitud que ellos asuman frente a la delación de la herencia, esto es, del Ilamamiento de la ley a aceptarla o repudiarla (art. 956 CC) ${ }^{4}$. Sólo si aceptan la herencia surge la posibilidad de materializar la sucesión procesal en un juicio pendiente donde el causante tenía la calidad de parte.

Esta sucesión procesal también podría darse en relación al legatario de especie; si fallece el causante que estaba litigando sobre la especie incluida como legado, el tercero beneficiario puede adquirir la calidad de parte, solicitando ingresar como parte la sucesión procesal ${ }^{5}$.

\footnotetext{
${ }^{3}$ En ciertos casos, por el carácter personalísimo del derecho que se discute en un proceso, la sucesión procesal no se puede producir.

${ }^{4}$ Cuando no se acepta la herencia por los herederos se puede designar un curador de herencia yacente (art. 481 CC).

${ }^{5}$ Una explicación de los posibles conflictos de derecho sucesorio vinculados a esta hipótesis, cfr. UGARTE VIAL, Jorge, "Protección de la legítima contra los legados de cuerpo cierto", Revista Chilena de Derecho Vol. 34, № 2, 2007, pp. 251-288. Sobre el tema, la CS, en sentencia de 2 de noviembre de 2009, resolvió que los herederos y legatarios, cuando se trata de legados de especie o cuerpo cierto, adquieren sus asignaciones al momento de la apertura de la sucesión, salvo que el llamado sea condicional, como se señala en el artículo 956 del Código Civil, caso en el cual la adquisición se producirá al momento de cumplirse la condición suspensiva (GJ №353, p. 102 y también en LegalPublishing: 42950).
} 
Sobre el tema, conviene considerar lo señalado por la Corte Suprema, en sentencia de 3 de abril de 2000, cuando declaró que:

"Séptimo: Que sobre esta materia debe tenerse presente que los herederos pueden encontrarse en tres situaciones: una, no tener conocimiento de la existencia de la herencia, sea testada o intestada; dos, tener conocimiento de ella, pero no desear aceptarla por razones de conveniencia personal o de otro orden; y tres, aceptarla lisa y llanamente, caso este último en que los acreedores del causante deben cumplir con lo que prescribe el artículo 1377 del Código Civil. La ley en todo caso dispone que si dentro de 15 días de abrirse la sucesión no se hubiere aceptado la herencia o una cuota de ella, ni hubiere albacea con tenencia de bienes que haya aceptado el encargo, el Juez a petición de cualquier interesado declarará yacente la herencia, designándole curador, cumpliéndose así lo dispuesto en los citados artículos 481 y 1240 del Código Civil y 849 del Código de Procedimiento Civil'.

En relación al hecho jurídico de la muerte y la sucesión procesal, se deben distinguir dos situaciones:

a) Si la parte que fallece tenía constituido mandato judicial

El mandato judicial no expira por la muerte del mandante (arts. 528 y 529 COT). Esto significa que el mandatario judicial, puede seguir tramitando el juicio o la gestión voluntaria, hasta su conclusión ${ }^{7}$.

La solución anterior hace una excepción a las reglas generales del Código Civil sobre terminación del contrato de mandato, atenuando el efecto que la muerte puede provocar en un proceso pendiente, sin solucionar directamente el problema de la sucesión procesal. En efecto, la posibilidad que el mandatario concluya el juicio será viable, mientras no sea necesaria la comparecencia personal del causante que le confirió el poder, como puede ser, por ejemplo, la citación a una audiencia de conciliación o de prueba. Si ello se dispone, no habrá más remedio que provocar la sucesión procesal de los herederos o el ingreso del curador de la herencia yacente, a falta de sucesores.

b) Si la parte comparece por sí misma

Cuando fallece alguna de las partes que obre por sí misma -hipótesis excepcional en nuestro sistema-, el proceso quedará en suspenso y su estado se comunicará a los herederos, para que comparezcan a hacer uso de su derecho en un plazo igual al de emplazamiento (art. $5^{\circ} \mathrm{CPC}$ ). Si los herederos no repudian

\footnotetext{
${ }^{6}$ CS, 3 de abril de 2000, Rol № 4237-1999, LegalPublishing: 16741.

${ }^{7}$ Esta es la solución de aplicación general en nuestro sistema, atendido que la Ley № 18.120, sobre comparecencia en juicio, admite en forma excepcional la tramitación sin contar con patrocinante y apoderado judicial.
} 
la herencia, pasan a adquirir la calidad de parte en el juicio, produciéndose de esa forma la sucesión procesal.

Como se puede apreciar, en el caso del deceso de la parte que comparecía personalmente en un proceso, la muerte obliga, siempre, a realizar la sucesión o cambio de parte.

\section{Fallecimiento de una de las partes, en el caso de derechos personalísimos}

Cuando fallece una de las partes, en un proceso cuyo objeto versa sobre derechos que revisten el carácter de personalísimos, el principio general es que la relación procesal concluya, al no ser factible provocar el cambio de la parte.

Las hipótesis más típicas de esta situación se presentan en el campo del derecho de familia, donde la intransmisibilidad de los derechos constituye la regla general.

Un ejemplo de lo anterior se da en la acción de divorcio, cuya titularidad pertenece exclusivamente a los cónyuges (art. $56 \mathrm{LMC}$ ). Esto significa que si durante el proceso fallece uno de los cónyuges, el matrimonio debe entenderse disuelto por la muerte, por tener la acción de divorcio un carácter personalísimo, que impide provocar una sucesión procesal con los herederos. Tal solución deja al cónyuge supérstite como heredero, aplicándose, en su beneficio, las reglas de sucesión por causa de muerte, que lo libran de perder sus derechos hereditarios y de alimentos, por la declaración del divorcio ${ }^{8}$.

Dicho de otra forma, el "derecho al divorcio" es algo que la ley reconoce exclusivamente al cónyuge, y por ende, no se podría mediante una sucesión procesal continuar discutiendo por terceros sobre la procedencia o improcedencia de la disolución del vínculo matrimonial.

Con todo, en otras situaciones, vinculadas al derecho de familia, el legislador ha previsto una solución diversa, autorizando la sucesión procesal si fallece una de las partes en un proceso pendiente. Un ejemplo de esta opción, se da en los juicios pendientes sobre determinación de la paternidad o maternidad, al autorizar que los legítimos contradictores puedan "continuar la acción" deducida con los herederos del difunto (art. 317 CC) ${ }^{9}$.

Por último, surge la duda si es factible provocar la sucesión procesal en procesos pendientes, cuando el derecho reclamado tiene un contenido extra

\footnotetext{
${ }^{8}$ Sobre el tema, con una síntesis de la jurisprudencia, BARría PAREDES, Manuel, "La muerte de uno de los cónyuges pendiente el juicio de divorcio", en Pizarro W., C. (Coord.), Estudios de Derecho Civil IV, LegalPublishing, Santiago, 2009, pp. 159-171.

${ }^{9}$ Sobre el tema, entre otros, CORRAL TALCIANI, Hernán, “¿Puede interponerse la acción de reclamación de filiación en contra de los herederos del supuesto padre fallecido?", Gaceta Jurídica N 346, Santiago, 2009. Con anterioridad, del mismo autor, "Determinación de la filiación y acciones de estado en la reforma de la ley No19.585, 1998", Revista de Derecho, Universidad Católica de Valparaíso, 1999, pp. 39-109.
} 
patrimonial. El problema se podría presentar, por ejemplo, en los juicios donde el actor reclamaba una indemnización por daño moral ${ }^{10}$, o solicitaba la protección jurisdiccional en una materia muy particular, como podría ser un determinado acto de discriminación. La solución en estos casos pasa, necesariamente, por definir si se trata o no de derechos transmisibles a sus sucesores.

\section{LA SUCESIÓN PROCESAL POR TRANSFERENCIA DE LA COSA LITIGIOSA}

La sucesión procesal por la transferencia de la cosa litigiosa, se puede originar por diversas causas.

A diferencia de otros ordenamientos, nuestro legislador aceptó la transferencia de los derechos que están siendo discutidos en juicio, mediante la celebración de un acto denominado cesión de derechos litigiosos (arts. 1911 al 1914 del CC). El art. 1911 del CC. señala que, "se cede un derecho litigioso cuando el objeto directo de la cesión es el evento incierto de la litis".

También puede producir la sucesión procesal otros actos, en cuanto comprendan la transferencia de los derechos que forman parte de una disputa judicial, como puede ser la compraventa, la permuta, una cesión de derechos personales, la cesión de contrato ${ }^{11}$, etc.

De igual forma, es posible que este cambio de partes sea justificada por la transferencia de derechos que se producen, por el solo ministerio de la ley, al perfeccionarse o realizarse una serie de actos jurídicos de la más variada naturaleza. Dentro de este grupo, los casos más frecuentes pueden provenir, entre otros, en el pago por subrogación (arts. 1608-1613 CC) ${ }^{12}$, en el pago de la indemnización en el contrato de seguro (art. 553 CCM), por la transferencia de la empresa (art. $4^{\circ} \mathrm{CT}$ ) o por la fusión de sociedades ${ }^{13}$.

\footnotetext{
${ }^{10}$ Esto no se debe confundir con la discusión que surge sobre la transmisibilidad de la acción a los herederos para reclamar por el daño moral, cuando el causante fallece sin haber iniciado el juicio. Sobre el tema cfr. Domínguez Aguila, Ramón, "Sobre la transmisibilidad de la acción por daño moral", Revista Chilena de Derecho Vol. 31 N³, 2004, pp. 493-514.

${ }^{11}$ Como en este caso se trata de un negocio jurídico trilateral, la cesión determina que el cesionario asuma todos los efectos de dicho acto, dentro de los que están la posibilidad de asumir su calidad de parte en la relación procesal (Sobre este tema, cfr. Figueroa YañeZ, Gonzalo, La asunción de deudas y la cesión del contrato, Editorial Jurídica de Chile, Santiago, 1984, pp. 79-83; Ríos LabBE, Sebastián, "Algunas reflexiones sobre la cesión de contrato", en Estudios de Derecho Privado, Editorial Jurídica de Chile, Santiago, 2008, pp. 309-334).

12 Sobre el tema, cfr. Dörr ZeGers, Juan Carlos, "La subrogación personal sin pago", Revista Chilena de Derecho Vol. 25, №1, 1998, pp. 57-64.

${ }^{13}$ En lo que respecta a la disolución o extinción de una persona jurídica, nuestro legislador no establece una solución general. La Ley $N^{\circ}$ 18.046, sobre Sociedades Anónimas para el caso de fusiones (que es la reunión de dos o más sociedades anónimas en una sola), de pleno derecho dispone que la sociedad absorbente sucede a las fusionadas en todos sus derechos y obligaciones. Sobre el tema, Prado Puga, Arturo, "Análisis doctrinal y jurisprudencial de la figura de la fusión", Gaceta Jurídica No 340, 2008, pp. 7-27.
} 
La falta de regulación legal en esta materia no ha sido obstáculo para aceptar la sucesión procesal, permitiendo en la práctica forense, por ejemplo, que el cesionario pueda hacerse parte en el juicio pendiente, sustituyendo a la parte original, con tal que acredite que en el contrato respectivo tiene el nombre de cedente.

Lo anterior es sin perjuicio de los límites que por razón de oportunidad se ha impuesto a este cambio, al declarar que no puede tener la calidad de parte una persona jurídica que suscribe un avenimiento en que le cedieron derechos litigiosos, ello por haberse suscrito dicho acto una vez que el juicio estaba terminado por sentencia ejecutoriada ${ }^{14}$.

En relación a la sucesión que se puede dar en el contrato de seguro, la C. de Ap. Concepción, en sentencia de 26 de noviembre de 1991 resolvió, "8..- Que mediante la subrogación legal establecida en el artículo 553 del Código de Comercio el asegurador tiene derecho propio contra el tercero causante del siniestro y ella se produce por el simple pago del seguro al asegurado sin necesidad de hacer valer otros medios probatorios para acreditar la subrogación (... $)^{\prime \prime 15}$.

\section{LA SUCESIÓN PROCESAL Y OBLIGACIONES DE GARANTía}

Aunque la sucesión procesal normalmente surge por la transferencia o la transmisión del derecho que es objeto del juicio, también puede provenir si se hacen efectivas ciertas obligaciones de garantía en un proceso pendiente.

El caso más evidente se da en la denominada citación de evicción, al permitir que un tercero sea citado a un juicio en curso, para que asuma la obligación de defensa que debe prestar a la parte compradora y evite la evicción de la cosa comprada, esto es, la pérdida de la cosa total o parcialmente por sentencia judicial ${ }^{16}$.

Si el tercero-vendedor comparece a dicho juicio se seguirá contra él la demanda, generándose de ese modo una sucesión procesal (1844 CC). Si el citado de evicción no comparece, la sucesión procesal no se produce, continuando el juicio entre el demandante y demandado original.

\footnotetext{
${ }^{14}$ CS, 27 de diciembre de 2000, MJ 3614. También existen algunos pronunciamientos donde se aprecia que no se ha aceptado este cambio de partes, entre otros, CS, 27 de agosto de 1992, LegalPublishing: 11987.

${ }^{15}$ C. de Ap. de Concepción, 26 de noviembre de 1991, LegalPublishing: 11719.

${ }^{16}$ La forma de hacer comparecer al tercero al juicio pendiente está prevista en los artículos 584 al 587 del CPC.
} 


\section{TRATAMIENTO PROCESAL Y EFECTOS DE LA SUCESIÓN}

Como la transferencia o la transmisión de los derechos en estado de litispendencia no repercuten de pleno derecho en el proceso en curso, el cambio de partes debe ser solicitado al juez que conoce del juicio.

El peticionario que quiera provocar esta modificación en la relación procesal deberá acreditar, según el caso, la transmisión o la transferencia del derecho, acompañando el certificado de defunción, la resolución judicial o administrativa que concedió la posesión efectiva a los herederos, el contrato o la cesión del derecho litigioso, la escritura pública que da cuenta de la fusión de sociedades, etc.

A falta de regla especial, la petición de cambio de partes se debe tramitar conforme a las reglas de los incidentes ordinarios.

La parte contra quien se solicita esta modificación podrá oponerse, aduciendo, entre otras razones, por ejemplo, que el acto jurídico donde consta la transferencia del derecho es nulo; que el solicitante no tiene efectivamente la calidad de heredero, al existir un juicio pendiente que cuestiona esa condición; que el acto traslaticio de dominio no tiene relación con el derecho que se encuentra controvertido en el juicio; que el acto de transferencia invocado es nulo o no fue realizado con las exigencias legales, etc.

Una vez que se ha decretado el cambio de partes, el sucesor pasa a ocupar el lugar de su causante. A partir de la notificación de esa declaración, podrá ejercer todos los derechos procesales, con la única limitación de aceptar todo lo obrado hasta el momento que se produce su ingreso.

Si no se solicita y autoriza judicialmente el cambio de parte, el proceso terminará con los sujetos que originalmente habían adquirido dicha calidad. 
